\title{
Kebijakan Pengembangan Koleksi Perpustakaan Universitas Islam Negeri Raden Fatah Palembang
}

\author{
Nurmalina \\ Universitas Islam Negeri Raden Fatah Palembang \\ nurmalina_uin@radenfatah.ac.id
}

\begin{abstract}
Collection is one of the requirements for the formation of a library in addition to library staff, facilities and infrastructure, a source of funding. Library collections are tailored to the needs of visitors, library types, and agency policies. The university library must have an adequate collection of both the number of titles and the number of copies. The collection is sufficient to support the implementation of education, research, and community service. In order for the development of a focused collection, a collection development policy is needed. This research uses a descriptive qualitative approach. This approach is used to describe the collection development that has been carried out by the library of UIN Raden Fatah Palembang along with the obstacles faced, as well as to collect data to make a written collection development policy. Data collection was carried out through observation, interviews and documentation. The findings in this study are that so far the UPT Library of UIN Raden Fatah has only carried out collection development activities by practice, but there is no collection development policy that will be used as a guide in carrying out collection development activities. This is so that the implementation of collection development activities is not well directed, because there are no guidelines in carrying out collection development activities.
\end{abstract}

Keywords: Collections; College Libraries; Collection Development; Collection Development Policies

\begin{abstract}
Abstrak
Salah satu syarat pembentukan perpustakaan selain sarana prasarana, sumber daya manusia, dana, dan koleksi. Jenis perpustakaan menentukan jenis koleksi yang akan menjadi koleksi perpustakaan. Koleksi tersebut harus dapat memenuhi kebutuhan pemustaka sebab kebutuhan pemustaka adalah prioritas di perpustakaan. Untuk memastikan kebutuhan pemustaka terpenuhi secara maksimal dibutuhkan sebuah pedoman dalam pengembangan koleksi. Agar pengembangan koleksi menjadi terarah dibutuhkan suatu kebijakan pengembangan koleksi. Untuk menggambarkan kebijakan pengembangan
\end{abstract}

TIK ILMEU: Jurnal IImu Perpustakaan dan Informasi, vol. 4, no. 2, 2020

IAIN Curup - Indonesia | ISSN 2580-3654 (p); 2580-3662 (e)

DOI: $10.29240 /$ tik.v4i2.1477 | p. 97-112 
koleksi di perpustakaan UIN Raden Fatah Palembang penelitian ini dilakukan serta mengidentifikasi kendala-kendala yang dihadapi. Pengumpulan data dilakukan melalui observasi, wawancara, dan dokumentasi.Hasil penelitian ini adalah kegiatan pengembangan koleksi sudah dilakukan sesuai dengan unsu-unsur kebijakan pengembangan koleksi akan tetapi belum secara maksimal karena tidak adanya pedoman tertulis. Kendala yang dihadapi tidak adanya sumber daya manusia yang khusus menangani pengembangan koleksi.

Kata Kunci: Koleksi; Perpustakaan Perguruan Tinggi; Pembinaan Koleksi; Kebijakan Pengembangan Koleksi

\section{A. PENDAHULUAN}

Bahan pustakaadalah bagian yang tidak bisa dipisahkan dengan keberadaan perpustakaan karena syarat untuk mendirikan perpustakaan perguruan tinggi seperti yang tercantum dalam buku "Pedoman Penyelenggaraan Perpustakaan Perguruan Tinggi" adalah terpenuhinya unsur koleksi dengan jumlah sebanyak 2.500 judul(Nasional, 2015). Koleksi tersebut dapat berupa karya cetak, karya tulis, karya rekam terdiri dari berbagai format atau media,dan memiliki nilai pendidikan serta dapat mendukung terlaksananya tri dharma perguruan tinggi tersebut.

Kebutuhan pemustaka di perpustakaan menjadi syarat utama dalam pengembangan koleksi. Perpustakan perguruan tinggi melayani kebutuhan mahasiswa, dosen dan tenaga kependidikan.Koleksi itu harus dapat memenuhi kebutuhan sivitas akademika perguruan tinggi tersebut baik dari kuantitas maupun kualitas. Hal ini sejalan dengan "Standards for Libraries in Higher Education (SLHE)" yang dikeluarkan oleh "Association of College and Research Libraries (ACRL)" yang memuat sembilan ranah baku mutu perpustakaan perguruan tinggi yaitu: "Institutional Effectiveness, Professional Values, Educational Role, Discovery, Collections, Space, Management/Administration/Leadership, Personnel, External Relations."Dalam unsur koleksi pada standar tersebut di atas dijelaskan bahwa koleksi harus dapat mendukung terlaksananya tri dharma perguruan tinggi dengan cara memberikan akses seluas-luasnya ke berbagai ragam bahan pustaka baik yang memiliki kualitas dan kedalaman subjek, maupun keragaman format dan mengikuti perkembangan zaman. (ACRL, 2018).

Dari standar ini dapat diketahui bahwa koleksi perpustakaan perguruan tinggi terdiri dari berbagai format yang bisa diakses secara offline ataupun online. Untuk bisa memberikan akses ke berbagai koleksi tersebut dibutuhkan infrastruktur atau sarana prasarana seperti komputer yang terhubung ke jaringan internet. Fasilitas yang diberikan perpustakaan ini 
dapat dimanfaatkan selama jangka panjang bukan hanya sesaat, untuk itu dibutuhkan pemeliharaam terhadap sarana prasarana perpustakaan ini.

Untuk mengetahui jenis koleksi di perpustakaan perguruan tinggi, secara terperinci dapat dilihat dalam "Peraturan Kepala Perpustakaan Nasional RI Nomor 13 Tahun 2017 tentang Standar Nasional Perpustakaan Perguruan Tinggi”. Disini dijelaskan perpustakaan perguruan tinggi dapat mengoleksi semua jenis koleksi baik format tercetak, tertulis, terekam, digital atau elektonik, non fiksi ataupun fiksi. Koleksi non-fiksi adalah buku wajib mata kuliah, bacaan umum, referensi, terbitan berseri dan lokal konten, laporan penelitian dan sebagainya. Untuk jumlah koleksi disesuaikan dengan mata kuliah paling sedikit tiga judul per mata kuliah. Sedangkan buku penunjang mata kuliah (pengayaan) jumlahnya dua kali buku wajib (Indonesia, 2017).

Banyaknya jenis koleksi dan ledakan informasi yang berdampak pada banyaknya koleksi yang diterbitkan dalam berbagai bentuk dan media menuntut perpustakaan harus dapat berinovasi menyesuaikan kebutuhan pemustakanya.Koleksi ini harus memiliki kreasi dan menarik serta bisa secepatnya digunakan pemustaka.Banyaknya permintaan pemustaka terhadap berbagai jenis koleksi harus direspon dengan peningkatan mutu koleksi. Mutu koleksi dapat ditingkatkan melalui pengembangan koleksi yang dijadikan kegiatan rutin di perpustakaan setiap tahunnya. Pengembangan koleksi melalui pengadaan bahan pustaka paling sedikit 2\% dari jumlah judul yang dimiliki atau paling sedikit dua ratus judul per tahun, perpustakaan dapat memilih yang lebih besar dari keduanya (Indonesia, 2011).

Pengembangan koleksi merupakan unsur yang sangat penting di perpustakaan, olehkarena itu perlu dibuat suatu kebijakan pengembangan koleksi. Kebijakan pengembangan koleksi adalah kerangka acuan yang berisi konsep-konsep dalam pengembangan koleksi perpustakaan (Indonesia, 2015). Ditambahkan Lasa HS (2009 : 245) bahwa pengembangan koleksi dibuat untuk menjaga agar koleksi selalu mutakhir dan dapat digunakan secara maksimal oleh pemustaka.

Dari standar-standar yang disebutkan di atas, diketahui bahwa perpustakaan perguruan tinggi harus mempunyai koleksi yang mencukupi kebutuhan sivitas akademikanya baik dari segi jumlah maupun subjeksubjeknya. Koleksi tersebut terdiri dari berbagai bentuk dan format serta mengikuti perkembangan zaman. Terpenting lagi bahwa koleksi tersebut menunjang proses belajar mengajar serta penelitian di perguruan tinggi itu. Untuk dapat mewujudkan semua itu, perpustakaan perlu membuat suatu kebijakan pengembangan koleksi secara tertulis. 
Berdasarkan latar belakang yang diuraikan sebelumnya, penulis berusaha untuk mengelaborasi kebijakan-kebijakan dalam pengembangan koleksi di Perpustakaan UIN Raden Fatah. Dengan harapan dapat ditemukan langkah-langkah strategis dalam menyusun kebijakan pengembangan koleksi. Sehingga perpustakaan tidak kehilangan peran sentralnya dalam mendukung pencapaian visi dan misi lembaga.

Penelitian mengenai topik yang sama dengan penelitian ini telah banyak dilakukan, seperti penelitian Arif Gunawan (2016), yang melihat pengembangan koleksi di Pusat Penelitian dan Pengembangan Perikanan. Penelitian ini menunjukkan pengadaan bersifat kurang aktif, karena dana tidak tersedia untuk pengadaan buku serta sarana prasarana seperti scanner dan komputer, masih kurang dan promosi tidak dilakukan secara online atau terbuka.

Penelitian berikutnya, Rahmat Iswanto (2017) meneliti tentang "Kebijakan Pengembangan Koleksi dan Pemanfaatannya di Perpustakaan Perguruan Tinggi (Analisis Penerapan Kebijakan Pengembangan Koleksi Perpustakaan Utama Universitas Islam Negeri Syarif Hidayatullah Jakarta". Penelitian ini memperlihatkan bahwa pelaksanaan pengembangan koleksi di perpustakaan diawasi oleh kebijakan pengembangan koleksi. Akan tetapi kebijakan ini perlu ditinjau kembali karena masih ada kebijakan yang belum tertuang dalam kebijakan tersebut.

Penelitian berikutnya kolaborasi antara Indah Wijaya Antasari dan Agoeng Noegroho (2019) yang mengambil judul "Pengembangan koleksi berbasis akreditasi program studi di perpustakaan Institut Agama Islam Negeri Purwokerto". Akreditasi program studi sebagai dasar pengembangan koleksi menjadi fokus dari penelitian ini. Seleksi koleksi tercetak menggunakan panduan akademik dan silabus mata kuliah, sedangkan koleksi digital menggunakan layanan booklessdan proquest.

Penelitian berusaha menjawab permasalahan tentangkebijakan pengembangan koleksi di Perpustakaan UIN Raden Fatah Palembang serta kendala-kendala yang dihadapi. Penelitian ini sebagai dasar dalam menyusun suatu kebijakan pengembangan koleksi yang dituangkan dalam suatu dokumen tertulis.

\section{B. HASIL DAN PEMBAHASAN}

Pengembangan koleksi di perpustakaan UIN Radan Fatah Palembang dalam rangka untuk memaksimalkan informasi sivitas akademika perguruan tinggi tersebut. Hal ini sejalan dengan definisi pengembangan koleksi yang dikemukakan oleh Evan (2005 : 70) bahwa pengembangan koleksi adalah proses untuk memastikan pemustaka terpenuhi kebutuhan informasinya 
baik secara ekonomis maupun ketepatan waktu, baik menggunakan sumbersumber internal maupun eksternal.

Menurut definisi ini agar pengembangan koleksi tersebut efektif perlu dibuatkan rencana yang berisi kelemahan dan kekuatan koleksi. Rencana tersebut dituangkan dalam suatu dokumen tertulis yang dapat digunakan sebagai panduan dalam mempertimbangkan subjek yang akan ditambahkan dan seberapa banyak subjek tersebut akan ditambahkan menjadi koleksi perpustakaan.

Definisi ini dipertegas lagi oleh Wahyuni \& Rahmah (2012) bahwa kebijakan pengembangan koleksi bisa dijadikan sebagai sarana/alat dalam menuntun segala kegiatan yang berhubungan dengan pendanaan, perencanaan, pemilihan dan pengadaan koleksi perpustakaan. Asas yang menjadi dasar kebijakan pengembangan koleksi adalah kemuktahiran, kelengkapan, kerelevan dan kerjasama. Kebutuhan pemustaka adalah yang utama dalam pengembangan koleksi. Pemustaka di perpustakaan perguruan tinggi adalah sivitas akademika seperti mahasiswa, dosen, tenaga kependidikan, peneliti, tenaga administrasi, yang memiliki kebutuhan informasi yang berbeda-beda.

Fungsi kebijakan pengembangan koleksi tertulis menurut Saleh (2010 : 3.3.) adalah bisa digunakan oleh pustakawan atau staf perpustakaan sebagai pedoman dalam pengembangan koleksi. Juga bisa digunakan sebagai sarana komunikasi untuk menyampaikan kepada pengguna mengenai koleksi yang sudah dimiliki perpustakaan dan rencana pengembangan selanjutnya. Terakhir berkaitan dengan dana yang dikeluarkan untuk pengadaan koleksi, melalui kebijakan pengembangan koleksi tertulis ini bisa mengatur prioritas dalam mengalokasikan berbagai sumber dana yang dapat dipertanggungjawabkan.

Pernyataan ini dipertegas lagi oleh Johnson (2009 : 74) yang melihat tujuan kebijakan pengembangan koleksi tertulis dari fungsinya. Pertama sebagai fungsi informasi, berisikan informasi tentang visi dan misi perpustakaan, koleksi yang dimiliki dan yang akan dimiliki. Informasi tersebut sebagai panduan untuk mengelola sumber-sumber pedanaan, ruangan dan sumber daya lainnya dalam menunjang koleksi. Fungsi kedua adalah sebagai perlindungan hak kebebasan intelektual dan mencegah sensor. 


\section{Unsur-Unsur Kebijakan Pengembangan Koleksi}

Penambahan koleksi di perpustakaan UIN Raden Fatah setiap tahun dilakukan dengan cara pembelian dan hadiah. Akan tetapi dalam melakukan kegiatan ini tidak ada pedoman atau panduan secara tertulis. Kegiatan pengembangan koleksi yang dilakukan UPT.Perpustakaan Raden Fatah, dapat digambarkan sebagai berikut:

- Kebijakan Seleksi

Seleksi dilakukan sebelum memutuskan koleksi yang akan diadakan, untuk membantu menyeleksi koleksi yang akan dibeli tersebut bisa menggunakan silabus mata kuliah di masing-masing program studi, katalog penerbit, dan browsing melalui internet. Pihak-pihak yang ikut terlibat dalam melakukan seleksi ini adalah ketua jurusan dan sekretaris jurusan, dosen, pustakawan dan kepala perpustakaan. Permintaan juduljudul buku yang dibutuhkan masing-masing prodi tersebut dikirim melalui surat yang ditujukan ke dekan nasing-masing fakultas.Kebijakan Pengadaankoleksi selama ini sebagain besar diperoleh dari pembelian, sebagian kecil lagi didapat melalui pemberian baik perorangan, instansi pemerintah, perguruan tinggi dan lembaga lainnya. Lalupembelian dilakukan oleh rekanan atau pihak ketiga yang telah ditunjuk oleh pejabat pembuat komitmen (PPK) sesuai dengan judul-judul yang yelah dibuat oleh perpustakaan

- Kebijakan Penyiangan

Penyiangan bahan pustaka dilakukan oleh semua pustakawan dan staf perpustakaan termasuk kepala perpustakaan. Penyiangan dilakukan sebulan sekali dengan cara shelving bersama sambil memilih dan mengeluarkan koleksi yang sesuai dengan kriteria berikut:

- Koleksi yang rusak ringan, sedang, dan parah

- Koleksi yang belum pernah dipinjam

- Koleksi out of date, tetapi bukan tentang sejarah

- Buku saku

Kegiatan ini dilakukan dengan tujuan agar koleksi yang ada di rak sesuai dengan kebutuhan pemustaka dan memberikan tempat kepada koleksi baru. Karena penambahan koleksi setiap tahun sedangkan jumlah rak tetap atau tidak bertambah.

- Kebijakan Evaluasi 
Evaluasi koleksi yang dilakukan pepustakaan dilakukan dengan cara melihat ketersedian koleksi di rak dan dari pangkalan data perpustakaan. Cara-cara yang lain seperti menyebar angket atau kuisioner untuk meminta pendapat pengguna, penilaian pakar, kajian sirkulasi, perbandingan dengan berbagai standar koleksi, belum pernah dilakukan. Oleh sebab itu, bila berdasarkan teori kebijakan evaluasi, apa yang dilakukan perpustakaan ini belum maksimal.

Dari penjelasan di atas, unsur-unsur kebijakan pengembangan koleksi sudah dilakukan perpustakaan UIN Raden Fatah Palembang, namun belum ada tuntunan atau pedoman secara tertulis dalam melakukannya, sehingga kebijakan tersebut sering berubah-ubah.

Untuk membuat suatu dokumen kebijakan pengembangan koleksi tertulis, penulis berusaha mengumpulkan data-data yang dibutuhkan. Hal ini sejalan dengan pendapatEvans (2005) bahwa jika ingin membuat suatu kebijakan pengembangan koleksi yang baik dibutuhkan berbagai data, seperti kekuatan dan kelemahan koleksi perpustakaan, masyarakat yang dilayani, sumber-sumber lain yang bisa digunakan.

- Kekuatan dan Kelemahan Koleksi perpustakaan

Untuk mengevaluasi koleksi agar diketahui kekuatan dan kelemahannya cara yang dapat digunakan yaitu dengan menggunakan metode terpusat pada koleksi, terpusat pada pengguna, pencocokan daftar, pendapat pakar, menggunakan data statistik, membandingkan dengan berbagai standar koleksi, kajian peminjaman,meminta pendapat pemustaka, menganalisa statistik peminjaman antar perpustakaan, melakukan kajian di tempat, memeriksa bahan pustaka di rak, dan evaluasi terbitan berkala (Almah, Hildawati, 2012).

Metode evaluasi koleksi ini dipertegas lagi oleh Syukrinur (2017) bahwa metode yang bisa digunakan adalah fokus pada penggunaaan data statistik, penilaian koleksi secara langsung dengan melakukan observasi.

Berdasarkan pendapat di atas, untuk mengetahui kekuatan dan kelemahan koleksi di perpustakaan, penulis menggunakan metode terpusat pada koleksi dengan melihat data statistik jumlah buku yang tersedia di perpustakaan. Koleksi tersebut dikelompokkan berdasarkan nomor klasifikasi, karena subjek bukudapat ditunjukkan dengan nomor klasifikasi. Banyaknya judul yang dimiliki berdasarkan subjeknya dapat menunjukkan kekuatan koleksi pada subjek tersebut begitu pula sebaliknya. 
Tabel 1. Koleksi Perpustakaan berdasarkan Klasifikasi

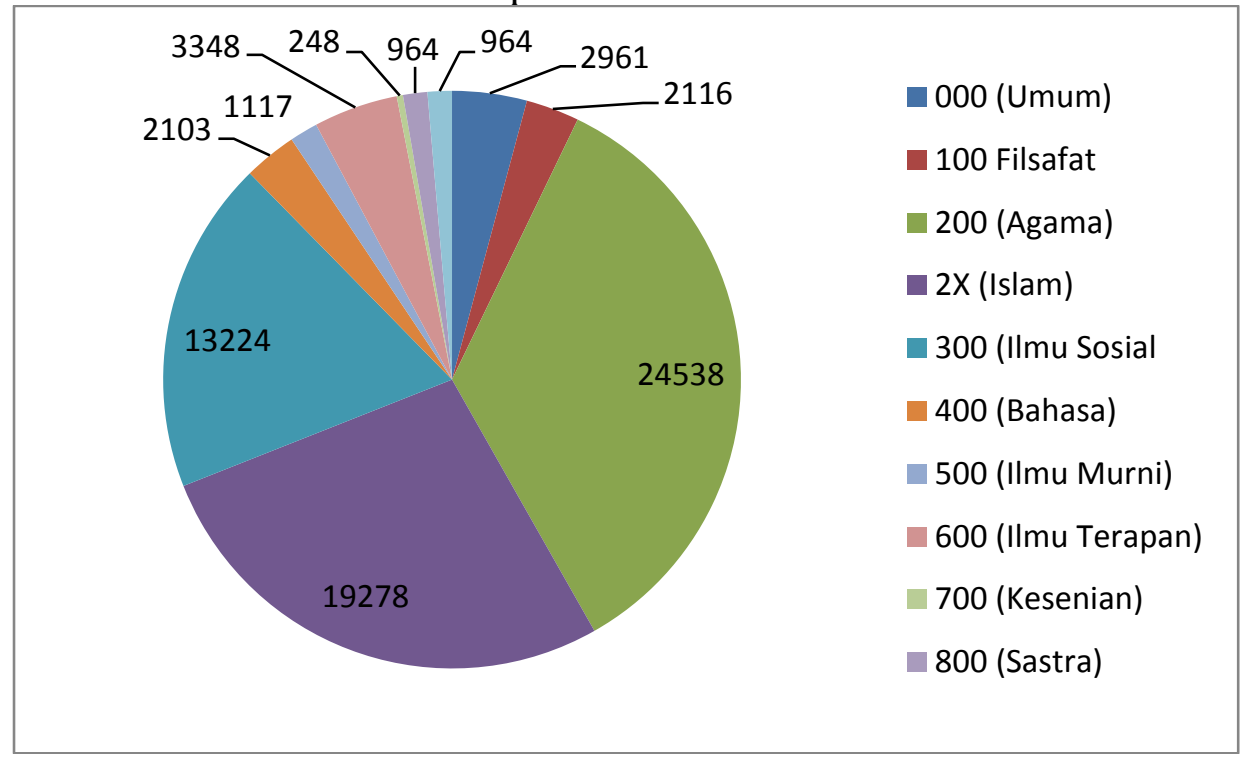

Kekuatan dan kelemahan koleksi perpustakaan dapat dijelaskan sebagai berikut:

1) Kekuatan koleksi terletak pada tiga subjek, pertama pada subjek Agama (200), kedua subjek Islam (2X) dan ketiga subjek Ilmu Sosial (300). Kekuatan koleksi ini disebabkan perpustakaan UIN Raden Fatah sebagai bagian dari perguruan tinggi Islam sehingga koleksinya sebagian besar tentang keislaman.

2) Sedangkan kelemahan koleksi terlihat dari sedikitnya jumlah judul yang dimiliki perpustakaan, yaitu:100 (Filsafat dan psikologi), 400 (Bahasa), 500 (Ilmu Murni), 600 (Ilmu Terapan), 700 (Kesenian), 800 (Kesusasteraan), 900 (Sejarah)

Dari penjelasan ini terlihatbahwa kelemahan koleksi terletak pada koleksi umum, bahasa, kesusasteraan, filsafat, psikologi, sejarah dan ilmu murni. Ini dikarenakan belum adanya progrm studi yang membutuhkan subjek tersebut. Seiring dengan adanya transformasi IAIN menjadi UIN dan dibukanya berbagai program studi baru maka koleksi-koleksi dengan subjek tersebut di atas banyak dibutuhkan. Sehingga ke depan penambahan koleksi di prioritaskan pada kelemahan koleksi ini.

- Masyarakat yang dilayani

Yang membedakan perpustakaan pergururan tinggi dengan perpustakaan lainnya adalah pemustaka atau yang lebih dikenal dengan masyarakat 
yang dilayani. Pemustaka di perpustakaan perguruan tinggi, adalah sivitas akademika, seperti peneliti, dosen, mahasiswa, tenaga kependidikan, staf administrasi. Masyarakat yang dilayani ini tergambar pada fakultas dan program studi berikut:

Tabel 2. Fakultas dan Prodi di UIN

\begin{tabular}{|c|c|c|}
\hline No. & Fakultas & Program Studi \\
\hline 1. & Tarbiyah dan Keguruan & $\begin{array}{l}\text { Pendidikan Agama Islam } \\
\text { Pendidikan Bahasa Arab } \\
\text { Pendidikan Bahasa Inggris } \\
\text { Pendidikan Matematika } \\
\text { Pendidikan Biologi } \\
\text { Pendidikan Kimia } \\
\text { Pendidikan Fisika } \\
\text { Pendidikan Madrasah Ibtidaiyah } \\
\text { Pendidikan Islam Anak Usia Dini } \\
\text { Manajemen Pendidikan Islam } \\
\text { S2 Manajemen Pendidikan Islam } \\
\text { S2 Pendidikan Agama Islam }\end{array}$ \\
\hline 2. & Syariah dan Hukum & $\begin{array}{l}\text { Hukum keluarga Islam } \\
\text { Hukum ekonomi syariah } \\
\text { Hukum Pidana Islam } \\
\text { Perbandingan Madzhab } \\
\text { S2 Hukum Tata Negara }\end{array}$ \\
\hline 3. & Ekonomi dan Bisnis Islam & $\begin{array}{l}\text { Ekonomi syariah } \\
\text { Perbankan Syariah } \\
\text { Manajemen Zakat dan Wakaf } \\
\text { S2 Ekonomi Syariah }\end{array}$ \\
\hline 4. & Dakwah dan Komnikasi & $\begin{array}{l}\text { Manajemen dakwah } \\
\text { Jurnalistik } \\
\text { Bimbingan dan Penyuluhan Islam } \\
\text { Komunikasi dan Penyiaran Islam } \\
\text { Pengembangan Masyarakat Islam }\end{array}$ \\
\hline 5. & $\begin{array}{l}\text { Ushuluddin dan Pemikiran } \\
\text { Islam }\end{array}$ & $\begin{array}{l}\text { Ilmu Al-Quran dan Tafsir } \\
\text { Perbandingan Agama } \\
\text { Aqidah dan Filsafat Islam }\end{array}$ \\
\hline 6. & Adab dan Humaniora & $\begin{array}{l}\text { Sejarah Kebudayaan Islam } \\
\text { Ilmu Perpustakaan } \\
\text { Bahasa dan Sastra Arab } \\
\text { Politik Islam }\end{array}$ \\
\hline
\end{tabular}


106 | TIK ILMEU: Jurnal IImu Perpustakaan dan Informasi, vol. 4, no. 2, 2020

\begin{tabular}{lll}
\hline & & S2 Peradaban Islam \\
\hline 7. & Sains dan Teknologi & Kimia \\
& & Biologi \\
& & Sistem Informasi \\
\hline 8. & Ilmu Sosial dan Ilmu Politik & Ilmu Politik \\
& & Ilmu Komunikasi \\
\hline 9. & Fakultas Psikologi & Psikologi Islam \\
\hline 10. & Pascasarjana & S2 Studi Islam \\
& & S3 Pendidikan Agama Islam \\
& & S3 Peradaban Islam \\
\hline
\end{tabular}

- Sumber-sumber lain yang bisa digunakan.

Saat ini koleksi perpustakaan yang ada di lingkungan UIN Raden Fatah Palembang baik perpustakaan pusat maupun fakultas bisa diakses secara online dengan menggunakan software yang sama dan saling terintegrasi. Koleksi masing-masing perpustakaan tersebut dapat diakses melalui Online Public Access Catalogue (OPAC) di alamat:

$\begin{array}{lll}\text { Perpustakaan Pusat } & : & \text { http://slims.radenfatah.ac.id } \\ \text { Perpustakaan fakultas } & : & \underline{\text { http://slims.radenfatah.ac.id/ftarbiyah/ }} \\ \begin{array}{l}\text { Tarbiyah } \\ \text { Perpustakan }\end{array} & : & \underline{\text { http://slims.radenfatah.ac.id/fuspi/ }} \\ \begin{array}{l}\text { Ushuluddin } \\ \text { Perpustakaan Fakultas }\end{array} & : & \underline{\text { http://slims.radenfatah.ac.id/fah/ }} \\ \begin{array}{l}\text { Adad dan Humaniora } \\ \text { Perpustakaan Fakultas }\end{array} & : & \underline{\text { http://slims.radenfatah.ac.id/fdak/ }} \\ \begin{array}{l}\text { Dakwah } \\ \text { Perpustakaan Ekonomi } \\ \text { dan Bisnis Islam }\end{array} & : & \underline{\text { http://slims.radenfatahFakultas.ac.id/febi/ }} \\ \begin{array}{l}\text { Perpustakaan } \\ \text { Pascasarjana }\end{array} & : & \underline{\text { http://slims.radenfatah.ac.id/fpps/ }}\end{array}$




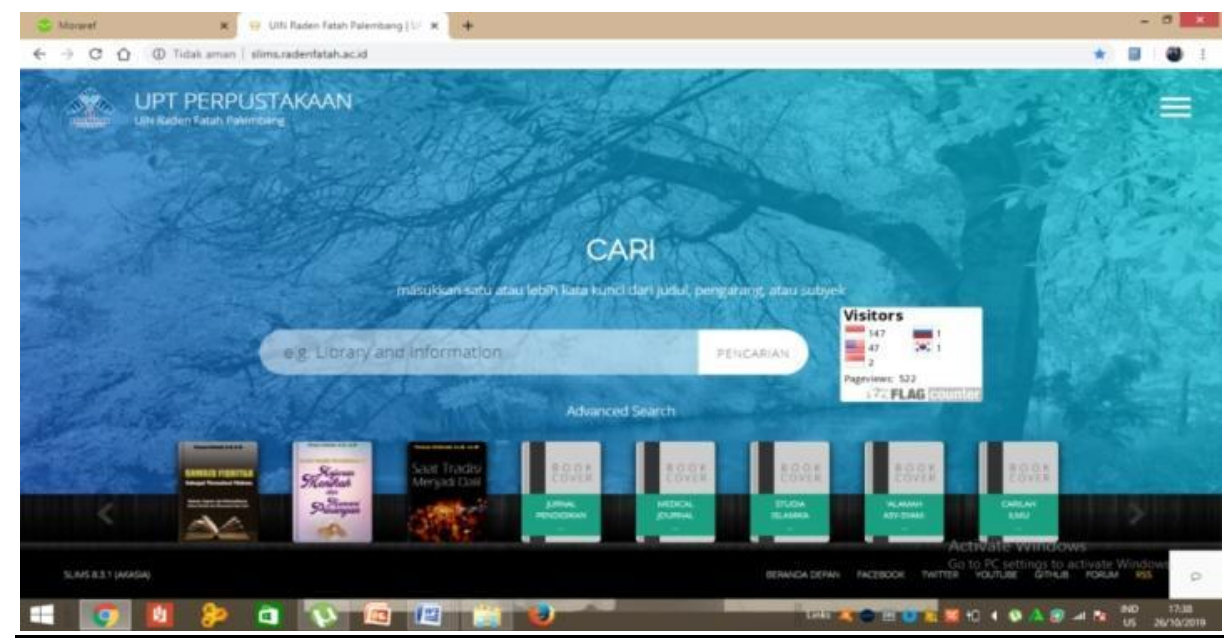

Gambar 1 : Katalog Online Perpustakaan Pusat

Selain OPAC masing-masing perpustakaan, koleksi perpustakaan di lingkungan UIN Raden Fatah ini juga terkumpul dalam Katalog Bersama di: http://slims.radenfatah.ac.id/katalogbersama. Dengan mengakses alamat web ini bisa diketahui keberadaan koleksi tersebut.

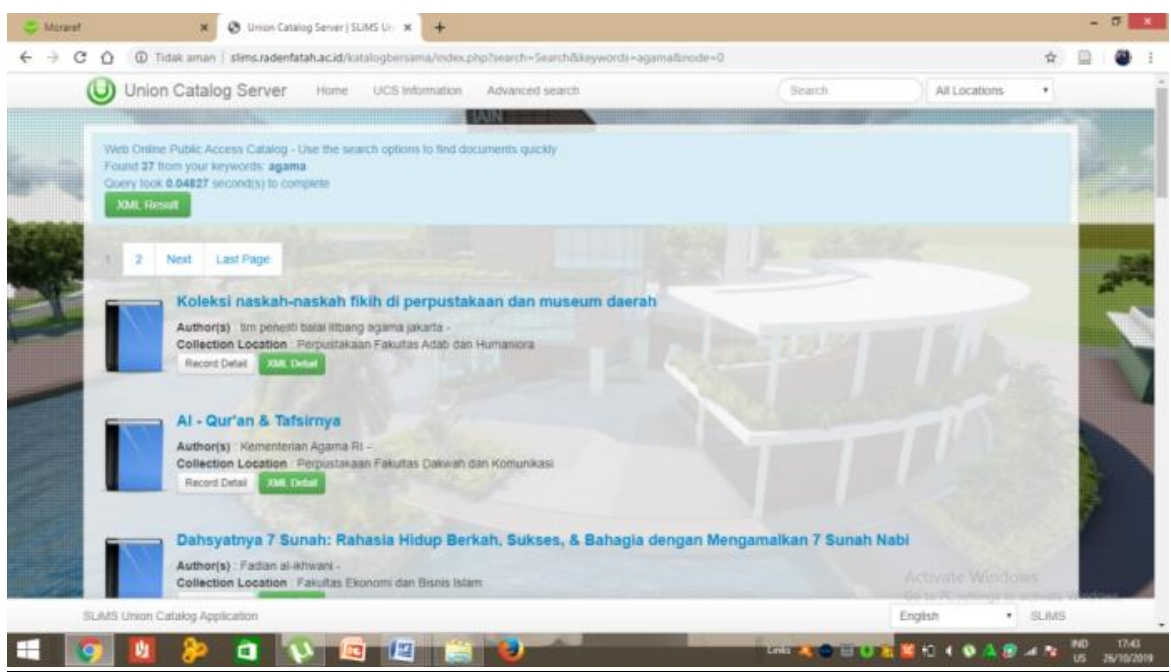

\section{Gambar 2 : Katalog Induk Perpustakaan}

Selain koleksi buku, ada pula jurnal yang diterbitkan oleh masingmasing fakultas di lingkungan UIN Raden Fatah. Jurnal-jurnal tersebut dapat diakses online di alamat: http://jurnal.radenfatah.ac.id/ 


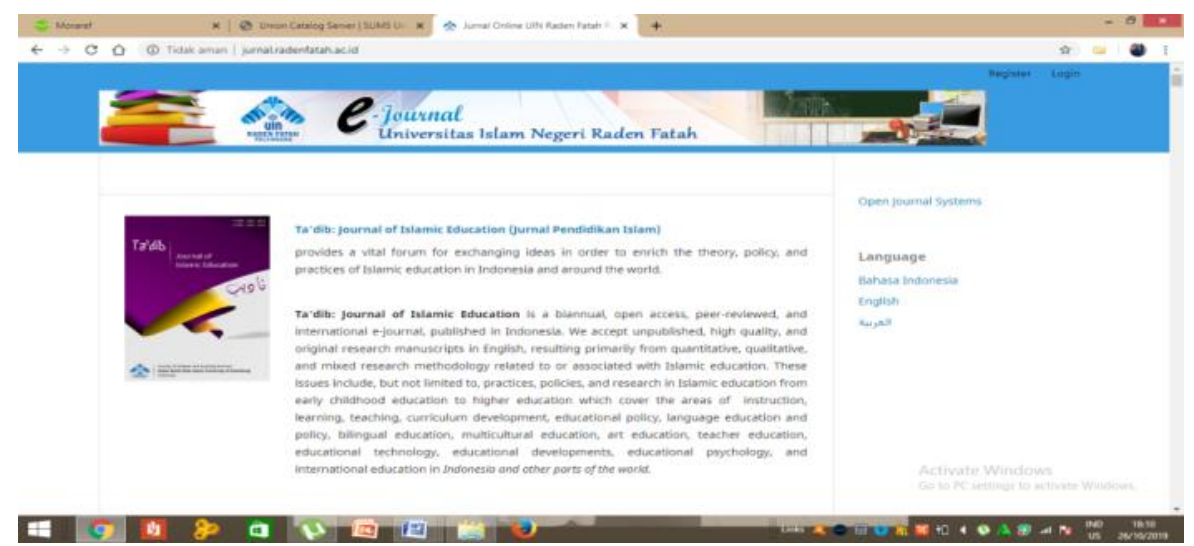

Gambar 3 : Jurnal Online (UIN Raden Fatah Palembang)

Jika pemustaka tidak bisa menemukan koleksi yang dicari di perpustakaan yang ada di lingkungan UIN Raden Fatah, bisa mendapatkannya dari perpustakaan lain yang yang sudah menjalin kerjasama dengan perpustakaan UIN Raden Fatah. Kerjasama tersebut tertuang dalam Perjanjian Kerjasama (PKS) baik berskala nasional maupun regional, seperti Perpustakaan Nasional RI, Dinas Perpustakaan dan Kearsipan Propinsi Sumatera Selatan, Asosiasi Perpustakaan Perguruan Tinggi Islam (APPTIS), Forum Kerjasama Perpustakaan Perguruan Tinggi Negeri (FKP2TN), Forum Kerjasama Perpustakaan Perguruan Tinggi Indonesia (FPPTI).

Koleksi berbagai perpustakaan di Indonesia dapat di akses melalui https://onesearch.id/. Portal ini berfungsi sebagai katalog induk nasional Indonesia, karena memuat katalog perpustakaan yang ada di seluruh Indonesia tidak dibatasi jenis perpustakaannya yang penting sudah online.

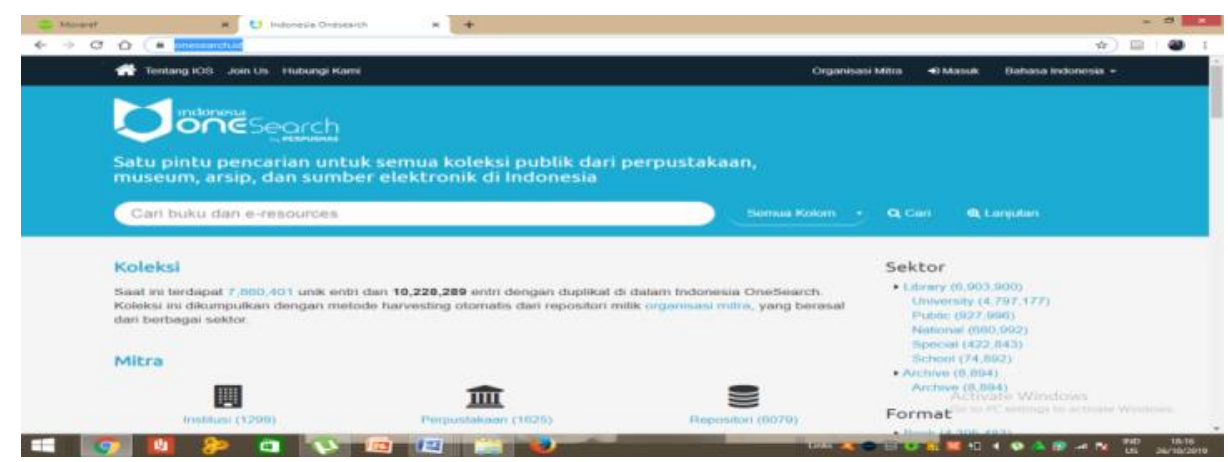

Gambar 4: Katalog Bersama Indonesia One Search

Selain jurnal-jurnal yang ada di lingkungan UIN Raden Fatah, untuk mencari jurnal perguruan tinggi lainnya yang ada di Indonesia, dapat diakses di: http://garuda.ristekdikti.go.id/ 
Data-data di atas akan digunakan sebagai pertimbangan dalam menyusun kebijakan pengembangan koleksi tertulis di perpustakaan UIN Raden Fatah Palembang.Tujuan dari penyusunan kebijakan ini adalah untuk menjaga agar koleksi tersebut mengikuti perkembangan zaman seperti perkembangan teknologi informasi dan tentunya sesuai dengan kebutuhan pemustaka. Juga akan digunakan sebagai pedoman atau arahan bagi pustakawan dan staf perpustakaan dalam pengadaan bahan pustaka dan juga penyiangan koleksi.

Kebijakan pengembangan koleki tertulis di perpustakaan UIN Raden Fatah Palembang yang akan dibuat terdiri dari:

a. Kebijakan Teknis Bahan Perpustakaan yang akan dikembangkan serta jumlah eksemplarnya.

Kemuktahiran koleksi tetap menjadi prioritas dalam pengembangan koleksi, format koleksi yang akan dikembangkan terdiri dari koleksi tercetak dan non cetak. Koleksi tercetak terdiri dari buku, serial atau terbitan berseri seperti koran, majalah, tabloid dan jurnal. Sedangkan koleksi non cetak seperti ebook, ejurnal, dan bentuk elektronik lainnya.

b. Kebijakan Teknis Jenis Koleksi yang akan dikembangkan.

Jenis koleksi yang akan dikembangkan adalah koleksi inti, pengayaan, penunjang penelitian (riset),koleksi rekreatif dan kultural.

c. Kebijakan Teknis Komposisi Koleksi yang akan dikembangkan

Koleksi inti adalah koleksi yang sesuai dengan kurikulum dan silabus matakuliah penambahannya $80 \%$ pertahun. Koleksi pengayaan untuk menunjang perkuliahan penambahan pertahun sebanyak $12 \%$. Koleksi penunjang penelitian misalnya jurnal elektronik, synopsis, indeks artikel, direktori, prosiding dan sebagainya, penambahannya sebanyak $6 \%$ per tahun. Koleksi rekreatif (novel, cerita, buku humor) dan koleksi kultural (koleksi Melayu, manuskripti) penambahannya sebanyak 2\% pertahun.

d. Kebijakan Teknis Subyek

Untuk subjek bahan pustaka yang akan dikembangkan mengacu pada program studi yang ada di lingkungan UIN Raden Fatah. Prioritas penambahan koleksi pada kelemahan koleksi seperti hasil evaluasi yang sudah dilakukan masih lemah pada koleksi-koleksi umum seperti filsafat dan psikologi, Bahasa, Ilmu Murni, Ilmu Terapan, Kesenian, Kesusasteraan dan sejarah.

e. Kebijakan Teknis Bahan Perpustakaan Hibah, Hadiah dan tukar menukar 
110 | TIK ILMEU: Jurnal IImu Perpustakaan dan Informasi, vol. 4, no. 2, 2020

Bahan perpustakaan yang diperoleh diluar pengadaan rutin, dapat dilakukan melalui hibah/wakaf, hadiah, tukar menukar. Prosedur pengadaan melalui sumber ini harus melalui proses seleksi yang dilakukan oleh tim seleksi harus memenuhi persyaratan yang telah ditetapkan perpustakaan.

f. Kebijakan penyiangan (weeding)

Koleksi yang ditarik dari rak harus melalui proses seleksi dan evaluasi terlebih dahulu yang dilakukan oleh tim weeding. Bahan pustaka yang akan ditarik dibuatkan daftar disusun berabjad menurut subjeknya. Penyiangan akan dilakukan apabila tim telah sepakat.

Kendala yang dihadapi dalam Melakukan Pengembangan Koleksi di UPT Perpustakaan UIN Raden Fatah Palembang

Kendala yang dihadapi dalam pengembangan koleksi di UPT Perpustakaan UIN Raden Fatah Palembang sebagai berikut:

1. Lambatnya respon program studi dalam menjawab surat yang diajukan perpustakaan sewaktu meminta judul-judul buku yang dibutuhkan program studi tersebut menjadi kedala ketika melakukan seleksi. Terkadang judul-judul yang diajukan tersebut sudah tersedia di perpustakaan atau tidak tersedia lagi di pasaran.

2. Dalam melakukan pengadaan, kendala yang dihadapi adalah tidak adanya kepanitian tim pengadaan bahan pustaka, sehingga ada pembagian tugas yang jelas masing-masing panitia tersebut.

3. Birokrasi, perpustakaan tidak membeli langsung bahan pustaka tersebut tetapi melalui rekanan yang ditunjuk oleh Pejabat Pembuat Komitmen (PPK), sehingga apabila ada buku yang tidak ada lagi di pasaran, proses pengadaan menjadi lama.

4. Tidak adanya sumber daya manusia atau pustakawan yang khusus menangani atau bertugas di bagian pengembangan koleksi.

\section{KESIMPULAN}

Pada prinsipnya pengembangan koleksi yang dilakukan perpustakaan UIN Raden Fatah Palembang sudah mengikuti unsur-unsur kebijakan pengembangan koleksi. Akan tetapi belum semua unsur tersebut dapat dipenuhi karena sewaktu melakukan kegiatan tersebut tidak menggunakan pedoman. Unsur-unsur pengembangan koleksi yang baru dilakukan seperti seleksi, pengadaan, penyiangan dan evaluasi. Evaluasi yang dilakukan masih terpusat pada koleksi belum kepada pengguna. Sedangkan kendala yang dihadapi masih kurangnya koordinasi dan komunikasi antara pihak 
perpustakaan dengan fakultas dalam melakukan seleksi dan masih kurangnya pemahaman sumber-sumber koleksi terbaru.

\section{DAFTAR RUJUKAN}

Association of College Reseaarch Library. (2018). Standards for Libraries in Higher Education. Retrieved from http://www.ala.org/acrl/standards/standardslibraries.

Almah, Hildawati. (2012). Optimalisasi Pengembangan Koleksi Perpustakaan Perguruan Tinggi. Jurnal Iqra, Volume 06(01), 19-28. Retrieved from http://oaji.net/articles/2015/1937-1429774556.pdf

Evans, G. ., \& M.Z.S. (2005). Developing Library and Information Center Collection. United States of America: Libraries Unlimited.

Gunawan, A., Darmanto, \& A.Lubis, N. R. (2016). Pengembangan Koleksi pada Perpustakaan Pusat Penelitian dan Pengembangan Perikanan. Jurnal Pari, Vol.2 No.1, 31-42. Retrieved from http://ejournalbalitbang.kkp.go.id

Indonesia. (2011). Standar Nasional Perpustakaan (SNP) 010. Jakarta : Perpustakaan Nasional

Indonesia. (2015). Kamus Besar Bahasa Indonesia. Jakarta: Gramedia Pustaka Utama.

Indonesia. (2017). Peraturan Kepala Perpustakaan Nasional Republik Indonesia Nomor 13 Tahun 2017 tentang Standar Nasional Perpustakaan. Jakarta: Perpustakaan Nasional

Iswanto, R. (2017). Kebijakan Pengembangan Koleksi dan Pemanfaatannya di Perpustakaan Perguruan Tinggi (Analisis Penerapan Kebijakan Pengembangan Koleksi Perpustakaan Utama Universitas Islam Negeri Syarif Hidayatullah Jakarta). Tik Ilmeu : Jurnal Ilmu Perpustakaan Dan Informasi, Vol.1 No.1. Retrieved from file:///C:/Users/youhe/Downloads/kdoc_o_00042_01.pdf

Johnson, P. (2009). Fundamentals of Collection Development and Management (Second Edi). Chicago: American Library Assosiation.

Lasa, H. (2009). Manajemen Perpustakaan. Yogyakarta: Gama Media.

Nasional, P. (2015). Pedoman Penyelenggaraan Perpustakaan Perguruan Tinggi. Jakar.

Saleh, A. R., \& Komalasri, R. (2010). Saleh, Abdul Rahman. Jakarta: Universitas Terbuka. 
112 | TIK ILMEU: Jurnal IImu Perpustakaan dan Informasi, vol. 4, no. 2, 2020

Syukrinur. (2017). Eavaluasi Koleksi: Antara Ketersedian dan Keterpakaian Koleksi. Libria, Vol. 9 No.(1), 93-102. Retrieved from file:///C:/Users/User/Downloads/1690-3352-1-SM.pdf

Wahyuni, S., \& Rahmah, E. (2012). Pengembangan Koleksi Perpustakaan di Perpustakaan Kopertis Wilayah X. Jurnal Ilmu Informasi Perpustakaan Dan Kearsipan, 1(September), 351-357. Retrieved from http://ejournal.unp.ac.id/index.php/iipk/article/view/1526 